\title{
Oenological attributes of the yeast Hanseniaspora vineae and its application for white and red winemaking
}

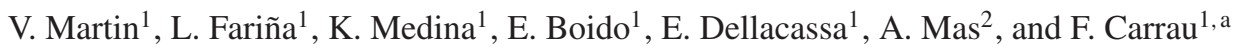 \\ ${ }^{1}$ Universidad de la República, Facultad de Quimica, Área Enología y Biotecnología de Fermentaciones, Montevideo, Uruguay \\ ${ }^{2}$ Biochemistry and Biotechnology Department, Faculty of Oneology, University Rovira i Virgili, Tarragona, Spain
}

\begin{abstract}
Flavour and some compounds associated with wine colour are known to be yeast strain-dependent. These metabolites are important for the sensory quality of wines, studies searching for increase aroma and color are a key area today in winemaking. The aim of this work was to study the oenological potential of the two main strains of Hanseniaspora vineae, native to Uruguay to better understand their successful application at winery level. It is known that these strains contribute with extracellular proteases and $\beta$-glucosidase enzyme activities that might increase cell lysis and flavor depending in grape varieties. Application and nutrient management of the process of these strains in production of white wines (Chardonnay, Macabeo and Petit Manseng) and red wine Tannat are discussed. Wines were evaluated to determine the volatile compounds composition and their effect compared to conventional processes. Low production of short and medium chain fatty acids and ethyl esters, and high production of acetate esters and isoprenoids are found compared to $S$. cerevisiae strains. The most outstanding characteristic of the species $H$. vineae was the production of benzenoids, phenylpropanoids and acetate esters. This behavior was reflected in the sensory evaluation, where all the fermentations performed with $H$. vineae were considered superior compared to Saccharomyces cerevisiae wine strains.
\end{abstract}

\section{Introduction}

Wine markets continue growing in brands quantity, and the challenge of product style differentiation is always more competitive and difficult to attract consumers attention. It is considered that regional consumption will be the main alternative for the many new brands that appear in the market. This is also in agreement with an opposite situation that is happening in the distribution channels, as every year there is a reduction in distribution companies in the main importer countries, such as the USA, UK and Germany. The use of non-conventional yeasts is a strategy to create unique wine profiles within an extensive market, where region identity is the challenge [1].

Returning to low input winemaking strategies to develop particular characteristics of the "terroir" that might differentiate their wines, is one of the ways that was followed by some winemakers in the last 20 years $[2,3]$. New sites and soil selection, minimal handling of the grapes and fertilizers addition, decrease irrigation, old vines recovery, are some of the topics that are being discussed in wine quality definition in the last two decades searching for complexity [4]. One of the key components of the terroir concept are the native yeast associated with the mature grapes of a particular region. In this presentation we showed our experience with a native grape yeasts of the apiculate group, Hanseniaspora vineae [5]. Since 2009 we have used this species for commercial wine production, with many interesting results firstly in white wines $[6,7]$, and now for red Tannat. Two strains genomes that were applied of this species were sequenced so as

a e-mail: fcarrau@fq.edu.uy to understand metabolic differences with the conventional $S$. cerevisiae strains [8]. Although there is an increase interest in non- Saccharomyces yeast application, there are still very limited commercial strains available for the winemaker $[9,10]$. We discuss here how we have applied small quantity production of liquid ferments that will improve non-conventional yeasts availability in particular regions, and a protocol for successful vinifications of these strains.

\section{Materials and methods}

\subsection{Yeast strains}

The commercial wine yeast strain used was $S$. cerevisiae ALG 804 (DSM, Denmark). The apiculate NS strain used was isolated from Tannat wine fermentation, $H$. vineae T02/5AF.

$H$. vineae was prepared by Lage y Cia in liquid sterile bags of 3 liters for inoculation at the winery to obtain an initial cell concentration of $5 \times 10^{5}$ cells $/ \mathrm{ml}$ in triplicate 400 liters bins for Tannat and $225 \mathrm{~L}$ barrels for white grapes Petit Manseng wines. Final population inoculated was checked by microscope counting and by plating in WLN medium where green dark colonies can be clearly associated with Hanseniaspora.

The commercial strain, S. cerevisiae ALG 804 was hydrated as instructed by the manufacturer and subsequent to microscope counting, the appropriate dilution of the rehydrated wine yeast was inoculated (at time 0 or 6 days after inoculation with strain $\mathrm{H}$. vineae T02/5AF in sequential co-inoculations) to obtain an initial cell concentration of $1 \times 10^{6}$ cells $/ \mathrm{ml}$. 
Table 1. Analytical parameters of Tannat wines produced with $H$. vineae compared to a conventional commercial yeast Saccharomyces cerevisiae ALG 804 (Sacch). Data showed are before and after malolactic Fermentation MLF, and during barrel and bottle aging. ND not determined.

\begin{tabular}{|c|c|c|c|c|c|c|c|c|c|c|}
\hline & \multicolumn{2}{|c|}{ Before MLF March 2013} & \multicolumn{2}{|c|}{ After MLF (May 2013) } & \multicolumn{2}{|c|}{ barrel aging Oct. 1st } & \multicolumn{2}{|c|}{ Aug 1st 2014 and Bottled } & \multicolumn{2}{|c|}{ Jul-15 } \\
\hline & Sacch & H. vineae & Sacch & H. vineae & Sacch & H. vineae & Sacch & H. vineae & Sacch & H. vineae \\
\hline Free SO2 mg/L & ND & ND & 11 & 12.4 & 17 & 22 & 22 & 25 & 18 & 21 \\
\hline Total SO2 mg/L & 7 & 9.8 & 26.52 & 23.2 & 51 & 45 & 66 & 53 & 60 & 48 \\
\hline Volatile Ac. g/L in Sulf & 0.255 & 0.27 & 0.5 & 0.48 & 0.54 & 0.4 & 0.6 & 0.49 & 0.59 & 0.44 \\
\hline Total Ac. $\mathrm{g} / \mathrm{L}$ in sulf & 4.65 & 5.1 & 4.1 & 4.3 & 4.3 & 4.3 & 4.2 & 4.1 & 4.2 & 4 \\
\hline pH & 3.5 & 3.4 & 3.81 & 3.65 & ND & ND & 3.67 & 3.64 & 3.72 & 3.67 \\
\hline Sugars g/L & 1.9 & 2.4 & 1.9 & 2.3 & ND & ND & 1.25 & 1.4 & $\mathrm{ND}$ & ND \\
\hline Alcohol \% Vol. & 13.2 & 13 & 13.2 & 13 & $\mathrm{ND}$ & $\mathrm{ND}$ & $\mathrm{ND}$ & ND & ND & ND \\
\hline OD 420nm & 9.415 & 9.44 & 7.86 & 7.5 & 7.04 & 6.51 & 6.8 & 6.3 & 7 & 5.9 \\
\hline OD 520nm & 22.075 & 21.81 & 15.4 & 15.17 & 12.73 & 11.78 & 10.7 & 9.7 & 9.3 & 7.9 \\
\hline OD 620nm & 4.035 & 3.985 & 3.53 & 3.12 & 2.96 & 2.56 & 3 & 2.5 & 3 & 2.1 \\
\hline CI & 35.55 & 35.25 & 26.79 & 25.79 & 22.73 & 20.85 & 20.5 & 18.5 & 19.3 & 15.9 \\
\hline Total Anthocyanin mg/L & 1710 & 1563.5 & 1061 & 931 & ND & ND & 577 & 628 & 386 & 351 \\
\hline Polyphenol Index & 88 & 88 & 84.8 & 81.7 & 80 & 76.2 & 75 & 74 & 69 & 67 \\
\hline
\end{tabular}

\subsection{Fermentation conditions}

The grape of Petit Manseng must contained $178 \mathrm{mg} \mathrm{N} / \mathrm{L}$ yeast assimilable nitrogen (YAN), $248 \mathrm{~g} / \mathrm{L}$ total sugars, $5.5 \mathrm{~g} / \mathrm{L}$ of total acidity was measured as sulphuric acid at $\mathrm{pH}$ 3.3. Grapes were crushed, cooled by refrigeration to $12^{\circ} \mathrm{C}$ and pressed with the addition of $3 \mathrm{~g} / \mathrm{Hl}$ of $\mathrm{SO}_{2}$, allowed to settle for $12 \mathrm{~h}$ and then transferred to three 2251 French oak barrels for each yeast treatment. Red grapes of Tannat were crushed, and no $\mathrm{SO}_{2}$ was added, so immediately were inoculated with the corresponding yeast treatments. Tannat grape contained $148 \mathrm{mgN} / \mathrm{L}$ of YAN, $235 \mathrm{~g} / \mathrm{L}$ of total sugars, $5.8 \mathrm{~g} / \mathrm{L}$ of total acidity and $\mathrm{pH} 3.3$.

Inoculation of the must was done immediately except for the spontaneous trials. Treatments were as follows: coferm- $H$. vineae (initially inoculated with $H$. vineae and then inoculated six days later with strain ALG 804), Commercial (inoculation with strain ALG 804 at time 0) and Spontaneous (without inoculation). Twenty-four hours after inoculation, $0.3 \mathrm{mg} / \mathrm{L}$ thiamine was added to all barrels. A supplementation of $100 \mathrm{mg} / \mathrm{L}$ with diammonium phosphate (DAP) and an extra $0.3 \mathrm{mg} / \mathrm{L}$ of thiamine and $1 \mathrm{~g} / \mathrm{L}$ of yeast extract were added when ALG 804 was added at day 6 to the $H$. vineae treatment. Fermentation activity was measured by juice density every day, together with temperature and room temperature was maintained at $20^{\circ} \mathrm{C}$. Procedures for wine chemical analysis and YAN levels by the formaldehyde method were described previously [11]. Samples for analysis were taken once a day, for cell growth measurement, using an improved Neubauer chamber and the numbers of dead cells were counted by the methylene blue-staining technique. Upon completion of alcohol fermentation, chemical and sensory analysis was done. Subsequently, malolactatic fermentation (MLF) was done using Oenococcus oeni VP41 (Lallemand, Montreal). All barrels were maintained at $18-22{ }^{\circ} \mathrm{C}$ and malic and lactic acid production during MLF was analysed by thin-layer chromatography [12]. After MLF completion $50 \mathrm{mg} / \mathrm{L} \mathrm{SO}_{2}$ was added followed by 2 months barrel ageing before bottling and final sensory analysis. All samples for analysis were filter sterilised (0.45 $\mu \mathrm{m}$ membrane) and the free $\mathrm{SO}_{2}$ content was then adjusted to $35 \mathrm{mg} / \mathrm{L}$, before and after MLF.

\subsection{Sensory analysis}

Duplicate sensory analysis was performed on fifteen samples, comprising three wines from each of the white wine treatments and two red Tannat wines. The three treatments as shown, are coded as follows, Spontaneous, Sacch and $H$. vineae, this last one refers to sequential co-fermentation. Sensory aroma description was made by a panel of eight established winemakers. Wines were presented in individual testing booths with normalised red lighting, to eliminate the colour perception of the white wine samples in flavour descriptions. Samples of $60 \mathrm{ml}$ were served at $18 \pm 1{ }^{\circ} \mathrm{C}$ in $250 \mathrm{ml}$, clear, tulip shaped wine glasses (ISO 3591, 1977) covered with a watch glass, and were identified with three digit random codes. Two samples were evaluated for aroma characteristics in each session. Panelists were required to rate secondary and tertiary tier terms using a 10-point intensity scale [13].

\subsection{GC and GC-MS analysis}

Aroma volatile compounds extraction of aroma compounds was done by adsorption and subsequent elution and separation from an Isolute (IST Ltd., Mid Glamorgan, U.K.) ENV+ cartridge packed with $1 \mathrm{~g}$ of highly, crosslinked, styrene-divinyl benzene (SDVB) polymer. Sample preparation and GC analysis was described previously [14].

Wine aroma components were identified by comparison of their Linear Retention Indices, with pure standards or data reported in the literature. Comparisons were also made with MS fragmentation patterns obtained with those in databases. GC-FID and GC-MS methods with an internal standard (1-heptanol) were used for quantitative purposes.

\subsection{Statistical analysis}

ANOVA of chemical and volatile compound analysis was done for the different fermentation treatments. ANOVA for sensory descriptors was done for different treatment and panel assessors' effect. Mean rating and Least Significant Differences (LSD) for each treatment were calculated from each analysis of variance with Statistica 7.1.

\section{Results and discussion}

In Table 1 we showed the basic wine quality parameters of Tannat red wines produced as an average of three processes with two yeast treatments for the Cerro Chapeu region. As it is shown wines obtained with $H$. vineae treatment give similar results in terms of final alcohol, volatile 
Table 2. Aroma compounds produced by $H$. vineae and $S$. cerevisiae of Tannat grapes of two different regions. Results are the average of triplicates and SD. *,** indicate significance at $p<0.05, p<0.01$ between the mean.

\begin{tabular}{|c|c|c|c|c|c|c|c|c|c|}
\hline \multirow[b]{2}{*}{ Alcohols } & \multicolumn{4}{|c|}{ Tannat Chapeu } & \multicolumn{4}{|c|}{ Tannat Melilla } & \multirow[b]{3}{*}{$* *$} \\
\hline & $\mathrm{H}$ vineae $+\mathrm{Sc} \mathrm{Ch}$ & SD & Sc Ch & SD & $\mathrm{H}$ vineae $+\mathrm{Sc} B$ & SD & Sc B & SD & \\
\hline 1-propanol & 40290 & 480 & 38970 & 2380 & 68600 & 980 & 28100 & 3570 & \\
\hline 2-methyl-1-propanol & 113280 & 3460 & 65340 & 1400 & 47180 & 380 & 42060 & 240 & ** \\
\hline 1-butanol & 129 & 6 & 140 & 0.3 & 251 & 10 & 283 & 10 & \\
\hline 3-methyl-1-butanol & 370520 & 2430 & 263210 & 33350 & 269180 & 3640 & 259340 & 1310 & * \\
\hline 1-hexanol & 966 & 59 & 920 & 6 & 1585 & 13 & 1478 & 15 & \\
\hline 2-ethyl-1-hexanol & 245 & 3 & 22 & 1 & 18 & 1 & 15 & 1 & \\
\hline 3-ethoxi-1-propanol & 151 & 10 & 435 & 5 & 407 & 6 & 1113 & 6 & ** \\
\hline benzyl alcohol & 80 & 14 & 94 & 4 & 203 & 5 & 165 & 5 & $*$ \\
\hline 2-phenethyl alcohol & 35076 & 279 & 41685 & 2113 & 23844 & 80 & 23298 & 120 & \\
\hline methanol & 59510 & 3540 & 54290 & 2090 & 100310 & 3040 & 84020 & 80 & \\
\hline methionol & 919 & 159 & 977 & 238 & 330 & 14 & 401 & 10 & \\
\hline Ethyl Esters & \multicolumn{2}{|l|}{$\mathrm{Hv}+\mathrm{Sc} \mathrm{C}$} & \multicolumn{2}{|l|}{ Sc C } & \multicolumn{2}{|l|}{$\mathrm{Hv}+\mathrm{Sc} \mathrm{B}$} & \multicolumn{2}{|l|}{ Sc B } & \\
\hline ethyl isobutirate & 50 & 3 & 33 & 0.03 & 22 & 2 & 37 & 1 & \\
\hline ethyl butirate & 85 & 4 & 72 & 1 & 157 & 4 & 159 & 5 & \\
\hline ethyl hexanoic & 175 & 16 & 161 & 2 & 195 & 6 & 239 & 9 & \\
\hline ethyl octanoic & 170 & 10 & 132 & 3 & 125 & 3 & 158 & 12 & \\
\hline ethyl decanoic & 45 & 3 & 33 & 1 & 43 & 1 & 46 & 1 & \\
\hline ethyl lactate & 18610 & 321 & 17079 & 324 & 10211 & 118 & 10450 & 120 & \\
\hline ethyl pyruvate & $\mathrm{nc}$ & $\mathrm{nc}$ & 4 & 1 & 24 & 1 & 40 & 1 & \\
\hline diethyl succinate & $3649 * *$ & 680 & 1245 & 131 & 616 & 17 & 662 & 16 & \\
\hline ethyl succinate & 48837 & 2876 & 59456 & 1431 & 25660 & 380 & 24605 & 200 & \\
\hline 2-hidroxi-glutarato de dietilo & 392 & 25 & 388 & 1 & 375 & 12 & 375 & 12 & \\
\hline Acetate Esters & \multicolumn{2}{|l|}{$\mathrm{Hv}+\mathrm{Sc} \mathrm{C}$} & \multicolumn{2}{|l|}{ Sc C } & \multicolumn{2}{|l|}{$\mathrm{Hv}+\mathrm{Sc} \mathrm{B}$} & \multicolumn{2}{|l|}{ Sc B } & \\
\hline 2-phenylethyl acetate & 134 & 25 & 133 & 21 & 433 & 5 & 193 & 6 & $* *$ \\
\hline isobutyl acetate & 60 & 0 & 40 & 0 & 65 & 1 & 74 & 1 & \\
\hline isoamyl acetate & 788 & 56 & 553 & 52 & 2050 & 45 & 2281 & 43 & \\
\hline ethyl acetate & 35810 & 2280 & 32610 & 7630 & 57440 & 1000 & 32930 & 360 & ** \\
\hline 1.3-propanediol diacetate & 465 & 78 & 970 & 16 & 467 & 2 & 772 & 20 & ** \\
\hline Acids & \multicolumn{2}{|l|}{$\mathrm{Hv}+\mathrm{Sc} \mathrm{C}$} & \multicolumn{2}{|l|}{ Sc C } & \multicolumn{2}{|l|}{$\mathrm{Hv}+\mathrm{Sc} \mathrm{B}$} & \multicolumn{2}{|l|}{ Sc B } & \\
\hline butanoic acid & 214.13 & 26.10 & 232.10 & 3 & 354 & 6 & 494 & 7 & * \\
\hline hexanoic acid & 664.89 & 97.35 & 755.32 & 47 & 840 & 3 & 956 & 12 & * \\
\hline octanoic acid & 845.06 & 143.38 & 950.54 & 20 & 988 & 21 & 1089 & 21 & * \\
\hline decanoic acid & 119.85 & 16.64 & 81.42 & 7 & 174 & 13 & 148 & 10 & * \\
\hline isobutanoic acid & 1660.65 & 220.26 & 1017.56 & 14 & 954 & 7 & 1464 & 8 & \\
\hline isovaleric acid & 619.35 & 13.56 & 979.22 & 50 & 548 & 7 & 637 & 9 & \\
\hline Lactones & \multicolumn{2}{|l|}{$\mathrm{Hv}+\mathrm{Sc} \mathbf{C}$} & Sc C & & $\mathbf{H v}+\mathrm{Sc} \mathrm{B}$ & & Sc B & & \\
\hline$\gamma$-butyrolactone & 761 & 47 & 1019 & 112 & 328 & 3 & 441 & 3 & \\
\hline pantolactone & 66 & 7 & 80 & 1 & 47 & 2 & 94 & 4 & \\
\hline Others & $\mathrm{Hv}+\mathrm{Sc} \mathrm{C}$ & $\mathrm{C}$ & Sc C & & $\mathrm{Hv}+\mathrm{Sc} \mathrm{B}$ & & Sc B & & \\
\hline 2,3-Butanodione & 152 & 3 & 224 & 12 & 206 & 4 & 250 & 10 & \\
\hline 2,3-Pentanodione & 67 & 5 & 65 & 3 & 170 & 3 & 168 & 15 & \\
\hline 3-hydroxi-2-butanone & 102 & 12 & 222 & 52 & 98 & 5 & 183 & 14 & \\
\hline acetaldehyde & 5250 & 810 & 3330 & 1380 & 8600 & 600 & 2370 & 310 & ** \\
\hline guaiacol & 102 & 16 & 116 & 8 & 220 & 25 & 88 & 6 & $* *$ \\
\hline 4-vinyl-guaiacol & 119 & 12 & 225 & 41 & 133 & 3 & 103 & 10 & \\
\hline 2,6-dimethoxy phenol & 379 & 16 & 592 & 16 & 867 & 51 & 438 & 15 & \\
\hline methyl vanillylether & 123 & 11 & 166 & 6 & 158 & 2 & 156 & 12 & \\
\hline 4-(4-hydroxy-3-methoxy-phenyl)butan-2-ol & 11 & 0 & 76 & 65 & 17 & 1 & 18 & 1 & \\
\hline zingerone & 3 & 0 & 4 & 0 & 12 & 0 & 10 & 0 & \\
\hline ethyl-b-(4-hydroxy-3-methoxy-phenyl-propionate & 7 & 0 & 10 & 1 & 28 & 0 & 19 & 1 & \\
\hline 3-oxo- $\alpha$-ionol & 29 & 2 & 30 & 0 & 51 & $0 . .20$ & 37 & 3 & * \\
\hline vomifoliol & 38 & 9 & 58 & 5 & 55 & 1 & 43 & 2 & * \\
\hline
\end{tabular}


Table 3. Aroma compounds produced by the 3 treatments of Petit Manseng barrel fermented. Results are the average of triplicates and SD. $* * *$ indicate significance at $p<0.05, p<0.01$ between the mean.

\begin{tabular}{|c|c|c|c|c|c|c|c|}
\hline \multirow[b]{2}{*}{ Alcohols } & \multicolumn{6}{|c|}{ Petit Manseng Melilla } & \\
\hline & Spontaneous & SD & Sacch & $\mathrm{SD}$ & H. vineae & $\mathrm{SD}$ & \\
\hline 1-propanol & 181 & 43.9 & 220 & 13.5 & 188 & 26.1 & \\
\hline 2-methyl-1-propanol & 3412 & 42.0 & 4507 & 10.8 & 2649 & 16.1 & $* *$ \\
\hline 1-butanol & 360 & 42.8 & 376 & 13.9 & 395 & 15.5 & \\
\hline 3-methyl-1-butanol & 71093 & 28.7 & 67586 & 13.2 & 65990 & 9.2 & \\
\hline 3-hydroxy-2-butanone & 235 & 56.6 & 145 & 47.6 & 119 & 16.8 & $* *$ \\
\hline 1-hexanol & 785 & 21.0 & 831 & 8.0 & 795 & 7.2 & \\
\hline 3-hexen-1-ol & 29 & 19.8 & 33 & 9.9 & 32 & 5.0 & \\
\hline 2-propanol & 20 & 14.4 & 16 & 25.7 & 20 & 11.8 & \\
\hline 2-ethyl-1-hexanol & 48 & 13.2 & 37 & 21.9 & 52 & 39.6 & \\
\hline 2-furanmethanol & 24 & 21.7 & 35 & 14.6 & 34 & 42.0 & \\
\hline benzyl alcohol / benzenemethanol & 49 & 8.8 & 44 & 22.2 & 40 & 23.5 & \\
\hline benzeneethanol / Phenethyl alcohol & 14757 & 11.3 & 12810 & 15.9 & 12135 & 15.3 & \\
\hline tyrosol & 4546 & 16.2 & 4738 & 22.3 & 2747 & 21.5 & $* *$ \\
\hline 3-methylthio-1-propanol & 340 & 16.9 & 324 & 14.0 & 300 & 30.8 & \\
\hline \multicolumn{8}{|l|}{ Esters } \\
\hline ethyl isobutirate & 84 & 43.6 & 108 & 13.9 & 109 & 22.0 & $* *$ \\
\hline acetate 3-methyl-1-butanol & 1248 & 33.9 & 987 & 34.9 & 953 & 20.2 & \\
\hline hexanoic acid ethyl ester & 248 & 13.1 & 245 & 16.2 & 283 & 9.4 & \\
\hline hexyl ester acetic acid & 84 & 28.7 & 54 & 63.1 & 52 & 25.4 & \\
\hline 2-hydroxy-propanoic acid & 23660 & 18.2 & 20447 & 30.2 & 24202 & 5.7 & \\
\hline ethyl ester octanoic acid & 528 & 14.1 & 549 & 4.9 & 625 & 7.7 & \\
\hline ethyl ester 3-hydroxybutanoic acid & 125 & 18.7 & 139 & 8.4 & 93 & 12.0 & \\
\hline ethyl ester decanoic acid & 228 & 11.8 & 222 & 12.8 & 247 & 12.3 & \\
\hline diethyl succinate & 3222 & 22.1 & 3239 & 16.4 & 2099 & 24.0 & $* *$ \\
\hline acetato de etilo & 17960 & 17.7 & 27820 & 22.1 & 42077 & 23.3 & $* *$ \\
\hline 1,3-propanediol acetate & 958 & 13.0 & 742 & 13.8 & 1065 & 12.9 & $* *$ \\
\hline ethyl hidroxy butyrate & 4429 & 11.5 & 4041 & 19.6 & 3357 & 14.9 & $* *$ \\
\hline 2-phenethyl acetate & 281 & 18.0 & 259 & 25.2 & 229 & 22.1 & \\
\hline butanedioic acid, hydroxy diethyl ester & 600 & 12.3 & 633 & 21.3 & 614 & 15.1 & \\
\hline ethyl succinate & 58273 & 21.4 & 52686 & 11.5 & 32247 & 18.0 & \\
\hline \multicolumn{8}{|l|}{ Acids } \\
\hline acetic acid & 726 & 23.9 & 711 & 14.8 & 1211 & 13.3 & $* *$ \\
\hline propanoic acid & 39 & 16.1 & 27 & 16.5 & 38 & 22.8 & \\
\hline isobutanoic acid & 451 & 5.7 & 476 & 10.0 & 365 & 9.4 & \\
\hline butanoic acid & 532 & 12.8 & 564 & 10.8 & 576 & 7.0 & \\
\hline isovaleric acid & 348 & 9.6 & 363 & 9.6 & 336 & 11.5 & \\
\hline hexanoic acid & 3786 & 19.5 & 3685 & 13.6 & 3629 & 13.6 & \\
\hline octanoic acid & 7649 & 11.7 & 7373 & 16.5 & 6444 & 12.9 & \\
\hline decanoic acid & 2578 & 18.2 & 2530 & 25.6 & 2421 & 19.0 & \\
\hline dodecanoic acid & 613 & 26.7 & 415 & 10.2 & 418 & 48.1 & \\
\hline \multicolumn{8}{|l|}{ other } \\
\hline g-butyrolactone & 565 & 22.4 & 521 & 20.9 & 541 & 16.1 & \\
\hline Pantolactone & 91 & 11.6 & 80 & 13.0 & 96 & 22.8 & \\
\hline \multicolumn{8}{|l|}{ Sum of aroma compounds } \\
\hline Alcohols & 76268 & 29.1 & 73929 & 12.6 & 70421 & 9.2 & $*$ \\
\hline Esters & 7131 & 3.6 & 6465 & 10.0 & 5855 & 8.8 & $*$ \\
\hline Fatty acids & 15196 & 10.7 & 14594 & 15.2 & 13525 & 12.6 & $*$ \\
\hline
\end{tabular}




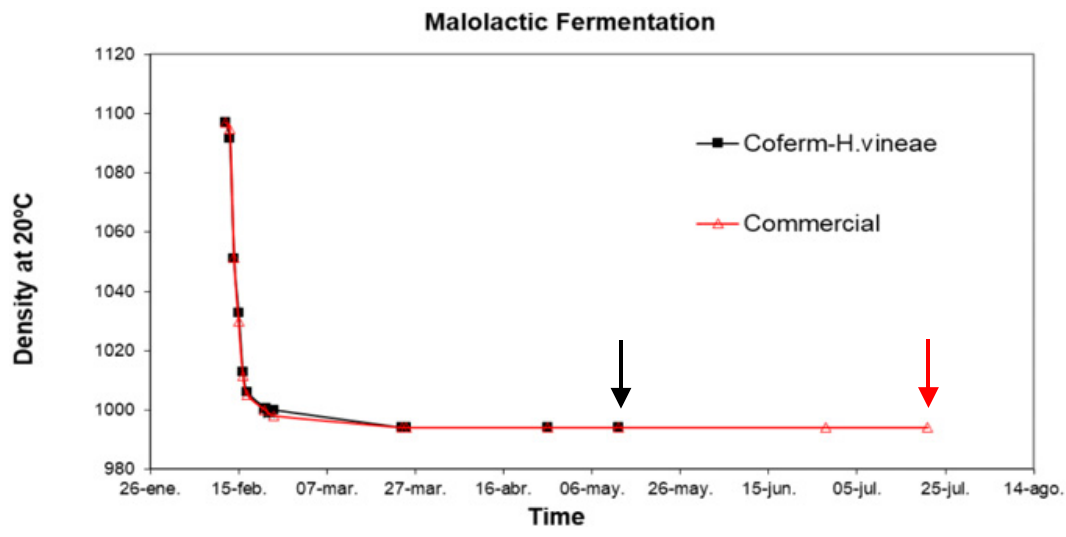

Figure 1. Malolactic fermentation is stimulated by $H$. vineae fermentations in Tannat. Similar results were obtained with barrel fermentation of Petit Manseng.

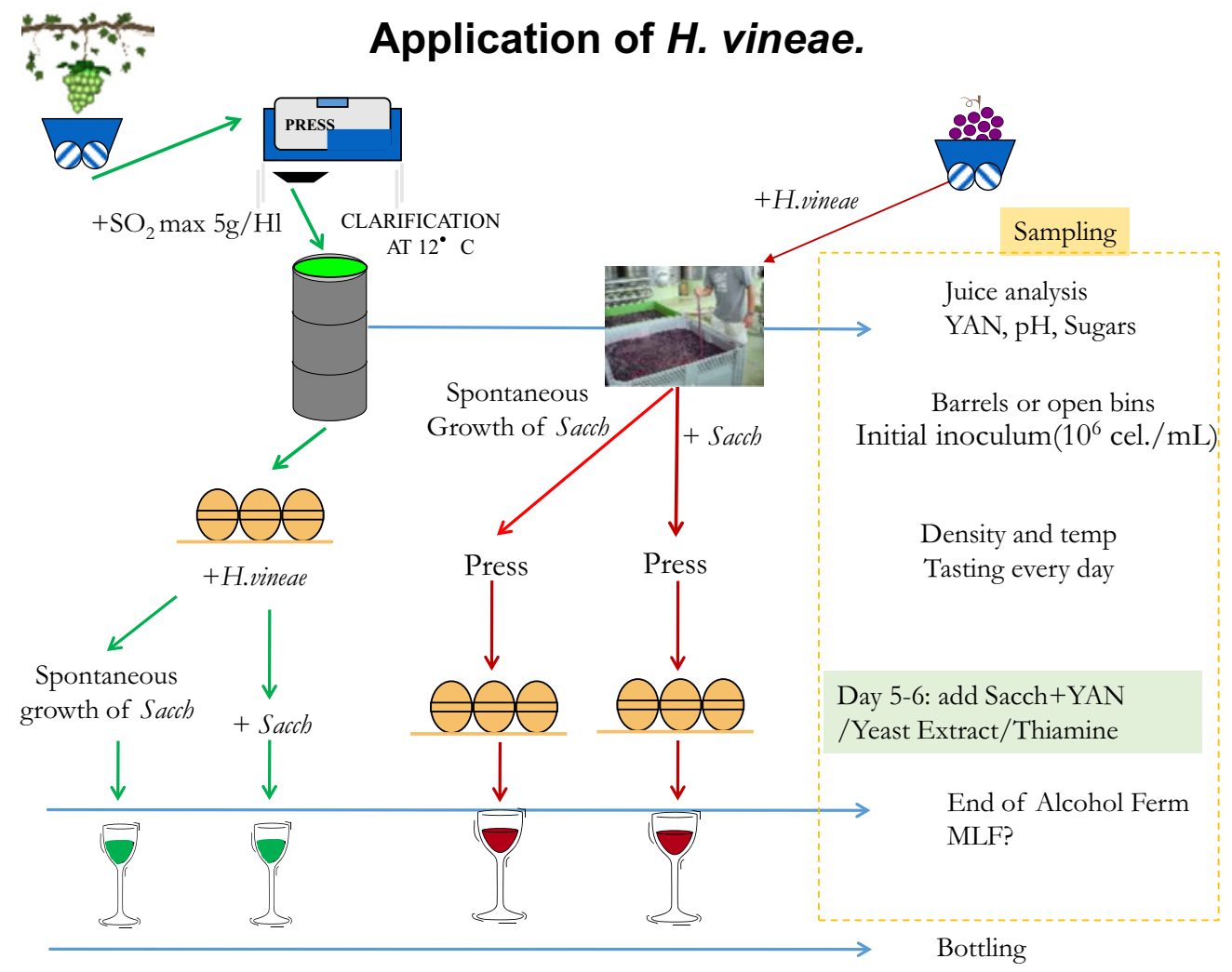

Figure 2. Application protocol for vinification in white and red wine with $H$. vineae strains.

acidity and final $\mathrm{SO}_{2}$. We found that the application of $H$. vineae facilitates the development of native yeast diversity during fermentation and also the malolactic fermentation MLF bacteria are stimulated as shown in Fig. 1. This result is in agreement with our previous work with white wine barrel fermented Chardonnay [6]. Similar results were obtained here also for white Petit Manseng barrel fermented. In Table 2, we present the data for Tannat vinificated in two different regions. Data are the average of triplicates, and from 47 compounds determined, 16 were significantly affected compared to the pure $S$. cerevisiae commercial strain utilized. Here we can found some consistent results with our white wine previous experiences with Chardonnay [6] and Macabeo [7]. Benzyl alcohol, 2-phenylethyl slvohol and ethyl acetate, guaiacol and an increase of norisoprenoids in the Tannat of Melilla were detected. Sensory analysis of the Tannat treatments showed an increase of fruity and caramel descriptors in $H$. vineae compared to the most obvious oak and herbal flavors of the Sacch treatment. In Table 3, the flavor compounds analysis for Petit Manseng barrel fermented is shown and from 42 compounds determined 9 were significantly affected $(p<0.01)$ compared to the conventional yeast treatment. Although it was demonstrated previously that 2-phenylethyl acetate and benzenoids were the main synthetize compounds by $H$. vineae in Chardonnay and Macabeo [6,7]. Results for Petit Manseng showed a similar behavior for these compounds than with the conventional yeast treatment. Figure 2 shows the application protocol defined as successful to apply in red and white wine winery scale production. Sluggish fermentations are avoided by a 
rational nutrient complementation of the co-inoculated strain at day 5 or 6 of the process. This is a simple operation that allowed the Sacch strain to obtained limited nutrients that were removed by $H$. vineae initial activity as it was demonstrated [15].

\section{Conclusions}

$H$. vineae showed oenological capacities for production of white and red wines, resulting in more complex sensory wines. Its moderate competitive capacity during vinification compared to Saccharomyces strains, help to understand the concept of "friendly yeast" that allowed to increase microbial diversity in the process. The nutrient management when sequential inoculation of $S$. cerevisiae is done should be the key activity to avoid a sluggish fermentation. It was shown that for Tannat wines the vinification process without addition of sulfites before fermentation and with sequential inoculation of S. cerevisiae after 6 days, resulted in wines of similar basic quality parameters than conventional vinification methods in terms of alcohol and volatile acidity. We presented an easy vinification protocol for making real wine experiments at the winery with or without commercial strains addition.

\section{References}

[1] F. Carrau, C. Gaggero, P.S. Aguilar, Trends Biotechnol. 33, 148 (2015)

[2] F.M. Carrau, Agrociencia 9, 387 (2005)

[3] D. Ramey, In Proceedings Australian Wine Industry Technical Conference, edited by C.S. Stockley,
R.S. Johnstone and T.H. Lee, A. N. S (Adelaide, Australia, 1995), pp. 26-29

[4] S. Tempère, A. Marchal, J.C. Barbe, M. Bely, I. Masneuf-Pomarede, P. Marullo, W. Albertin, Appl. Microbiol. Biotechnol. 102, 3995 (2018)

[5] V. Martin, M.J. Valera, K. Medina, E. Boido, F. Carrau, Fermentation 4.3, 76 (2018)

[6] K. Medina, E. Boido, L. Fariña, O. Gioia, M.E. Gomez, M. Barquet, C. Gaggero, E. Dellacassa, F. Carrau, Food Chem. 141, 2513 (2013)

[7] J. Lleixà, V. Martín, M. Portillo, C. del, F. Carrau, G. Beltran, A. Mas, Front. Microbiol. 7, 338 (2016)

[8] F.M. Giorello, L. Berná, G. Greif, L. Camesasca, V. Salzman, K. Medina, C. Robello, C. Gaggero, P.S. Aguilar, F. Carrau, Genome Announc. 2 (2014)

[9] C. Varela, A.R. Borneman, Yeast, 34, 111 (2017)

[10] N.P. Jolly, C. Varela, I.S. Pretorius, FEMS Yeast Res. 14, 215 (2014)

[11] B.W. Zoecklein, K. Fugelsang, B.H. Gump, F.S. Nury, Wine Analysis and Production (Chapman \& Hall, New York, 1995)

[12] E. Boido, E. Dellacassa, F. Carrau, P. Moyna, J. Planar Chromatogr. - Mod. TLC 12, 269 (1999)

[13] A. Gámbaro, E. Boido, A. Zlotejablko, K. Medina, A. Lloret, E. Dellacassa, F. Carrau, Aust. J. Grape Wine Res. 7, 27 (2001)

[14] E. Boido, A. Lloret, K. Medina, L. Farñia, F. Carrau, G. Versini, E. Dellacassa, J. Agric. Food Chem. 51, 5408 (2003)

[15] K. Medina, E. Boido, E. Dellacassa, F. Carrau, Int. J. Food Microbiol. 157, 245 (2012) 